\title{
ALTERAÇÕES QUÍMICAS DE UM CAMBISSOLO HÚMICO CAUSADAS POR FLORESTAMENTO COM Pinus taeda EM ÁREA DE CAMPO NATURAL
}

\author{
Simone Filipini Abrão ${ }^{1 *}$, Suzana Ferreira da Rosa ${ }^{2}$, Dalvan José Reinert ${ }^{3}$, José Miguel Reichert ${ }^{3}$, \\ Deonir Secco ${ }^{4}$ Ângelo Augusto Ebling ${ }^{1}$ \\ ${ }^{1 *}$ Universidade Federal do Paraná, Programa de Pós-Graduação em Engenharia Florestal, Curitiba, Paraná, Brasil - \\ simone.abrao@ufpr.br; ebling@ufpr.br \\ ${ }^{2}$ Instituto Federal de Educação, Ciência e Tecnologia do Rio Grande do Sul, Ibirubá, Rio Grande do Sul, Brasil - \\ suzanafdr@hotmail.com \\ ${ }^{3}$ Universidade Federal de Santa Maria, Departamento de Solos, Santa Maria, Rio Grande do Sul, Brasil - dalvan@ufsm.br; \\ reichert@ufsm.br \\ ${ }^{4}$ Universidade Estadual do Oeste do Paraná, Centro de Ciências Exatas e Tecnológicas, Cascavel, Paraná, Brasil - \\ deonir.secco@unioeste.br
}

Recebido para publicação: 08/04/2014 - Aceito para publicação: 20/02/2015

\begin{abstract}
Objetivou-se verificar se a introdução da espécie Pinus taeda L. em solo sob campo natural pode degradar quimicamente a qualidade do Cambissolo Húmico. O estudo foi conduzido na região dos Campos de Cima da Serra, no município de Cambará do Sul, RS, Brasil. Para isso, foram escolhidas duas áreas de estudo, uma em primeira e a outra em segunda rotação, com 13 anos de idade. Para cada povoamento, foi avaliada conjuntamente uma área de campo natural adjacente (testemunha). Em cada área, foram abertas cinco trincheiras e coletadas amostras de solo nas profundidades $0,0-0,05 ; 0,05$ 0,20; 0,20-0,40 e 0,40-0,60 m. Os atributos químicos do Cambissolo Húmico foram alterados, com reduções no teor de bases trocáveis (cálcio e magnésio), nas camadas superficiais, enquanto os teores de fósforo apresentaram-se maiores nas áreas com povoamentos. O pínus também alterou os níveis de alumínio trocável e a acidez do solo, elevando os teores de alumínio e reduzindo o $\mathrm{pH}$. Os teores de carbono orgânico total e nitrogênio total foram reduzidos na camada mais superficial do solo, porém esse comportamento muda na segunda rotação, em que a área com plantio de pínus manteve níveis de $\mathrm{C}$ e $\mathrm{N}$ similares aos do campo original.

Palavras-chave: Acidez; nitrogênio; matéria orgânica; relação C/N.
\end{abstract}

Resumo

\begin{abstract}
Impact of afforestation with Pinus taeda in chemical attributes of a Haplumbrept. The This research aimed to determine whether Pinus taeda L. cultivation on a Haplumbrept, previously under native grassland, would degrade soil chemical quality. The study was conducted in the region of Campos de Cima da Serra, in Cambará do Sul, RS, Brazil. We selected two areas, one in the first and another in the second rotation, aged 13 years. A contiguous area with grassland (control) was studied for each pine stand. In each area, five trenches were opened and soil samples collected in $0.0-0.05,0.05-0.20$, $0.20-0.40$ and $0.40-0.60 \mathrm{~m}$ soil layers. Chemical soil analyses revealed reduction in exchangeable bases (calcium and magnesium) in surface layers, but phosphorus content was higher in areas with pine stands. The forest also altered exchangeable aluminum and soil acidity, increasing the contents of aluminum and reducing $\mathrm{pH}$. Total organic carbon and total nitrogen were reduced in the surface, but this behavior changed in the second rotation, where soil with pine maintained $\mathrm{C}$ and $\mathrm{N}$ contents similar to the original field.
\end{abstract}

Keywords: Acidity; nitrogen; organic matter; $\mathrm{C} / \mathrm{N}$ relation.

\section{INTRODUÇÃO}

Os Cambissolos apresentam, naturalmente, altos níveis de matéria orgânica nos horizontes superficiais, baixos teores de $\mathrm{Ca}, \mathrm{Mg}$ e $\mathrm{K}$, baixo $\mathrm{pH}$ e altos níveis de alumínio trocável, características resultantes do clima frio e úmido predominante na região de ocorrência, que favorecem o acúmulo de 
matéria orgânica, mas ao mesmo tempo induzem à alta taxa de lixiviação, tornando esses solos pobres em nutrientes (BRASIL, 1973). Esse aspecto é comprovado por meio da extrema adaptabilidade das espécies de gramíneas nesse ambiente (BOLDRINI et al., 2009), devido ao ecossistema campo nativo, com predomínio de gramíneas, ser pouco exigente e se manter por meio da ciclagem de nutrientes (REISSMANN; WISNIEWSKI, 2005).

A substituição do campo natural por florestamentos é motivo de inquietação, principalmente quando se refere às áreas de maior susceptibilidade à escassez de recursos nutricionais, como as de ocorrência de Cambissolo Húmico. Apesar da baixa exigência nutricional da espécie Pinus taeda L., os plantios de pínus podem reduzir os teores de nutrientes no solo. Nesse sentido, a implantação de florestamentos pode promover alterações nos atributos químicos do solo em função do tempo de cultivo, reduzindo as bases trocáveis e agravando ainda mais a fertilidade do solo (LEPSCH, 1980). Logo, o período de rotação é fundamental quando se espera a manutenção da produtividade dos sítios, considerando um período mínimo necessário para reposição de nutrientes, ou seja, para que o solo possa adquirir uma reserva de nutrientes suficiente para a próxima rotação. Períodos curtos têm sido um dos principais fatores responsáveis pelo exaurimento do solo, por meio da exportação de nutrientes proporcionada pela colheita e o uso intensivo do solo.

Em solos sob diferentes coberturas (campo nativo, pínus, reflorestamento de araucária e araucária nativa), foram observados, em todas as camadas avaliadas, valores menores de $\mathrm{pH}$ nos plantios de $P$. taeda, com 12 e 20 anos de idade, apresentando valores entre 4,5 e 5,3 (MAFRA et al., 2008). Os valores de $\mathrm{pH}$ encontrados não comprometem o desenvolvimento da espécie, visto que o $P$. taeda cresce rapidamente em solos que apresentam $\mathrm{pH}$ dentro de uma faixa de 4,5 a 6,0.

Em áreas de conversão do cerrado em floresta de Pinus caribaea, pastagem e semeadura direta em um Latossolo, nas camadas superficiais, quando da conversão de áreas naturais (cerrado) em plantio direto e florestamento de pínus, os teores de carbono orgânico total permaneceram semelhantes aos originais (WENDLING et al., 2012). Mafra et al. (2008) também verificaram que os reflorestamentos com pínus e araucária mantiveram os estoques de carbono orgânico, na camada mais superficial, em níveis semelhantes aos da mata e campo nativo. Por outro lado, os teores de carbono orgânico não são apenas elevados no solo, mas também na serapilheira, os quais foram maiores nas áreas com P. taeda e com floresta nativa, quando comparados com o campo, mostrando o potencial que os resíduos florestais têm em devolver carbono ao solo (BRUN, 2008).

Diante dessas evidências, torna-se necessário aprofundar os estudos das possíveis alterações químicas do solo promovidas pela conversão do campo natural em povoamentos de $P$. taeda ao longo das rotações, visto que a grande maioria das pesquisas não considera o solo sob vegetação original ou não avalia as sucessivas rotações, as quais podem refletir as condições da qualidade do solo de um determinado período. Assim, o objetivo foi verificar se a introdução da espécie $P$. taeda em solo sob campo natural pode degradar quimicamente a qualidade do Cambissolo Húmico.

\section{MATERIAL E MÉTODOS}

\section{Caracterização dos locais de estudo e coleta de amostras de solo}

O estudo foi conduzido no município de Cambará do Sul, RS, em um Cambissolo Húmico Alumínico típico (EMPRESA BRASILEIRA DE PESQUISA AGROPECUÁRIA (EMBRAPA), 2013), com clima tipo $\mathrm{Cfb}$ (Köppen), utilizando povoamentos florestais em primeira e segunda rotação de $P$. taeda e em campo natural adjacente, adotado como testemunha. A área de estudo de primeira rotação (RT1), com coordenadas geográficas de $29^{\circ} 06^{\prime}$ de latitude Sul e $50^{\circ} 11^{\prime}$ de longitude Oeste, possui 20,13 ha plantados com P. taeda. O plantio foi realizado sem adubação, após marcação e coroamento manual.

A segunda área de estudo trata-se de uma área de reforma, ou seja, foi implantada onde já havia anteriormente o plantio com $P$. taeda e, portanto, de segunda rotação (RT2). Com coordenadas geográficas de $28^{\circ} 53^{\prime}$ de latitude Sul e $50^{\circ} 07^{\prime}$ de longitude Oeste, abrange uma área de 636,14 ha florestados com a espécie $P$. taeda. O plantio foi realizado sem adubação, após queima, marcação e coroamento manual. A área de segunda rotação vem sendo utilizada com florestamento de pínus há aproximadamente 30 anos.

Os dois povoamentos foram implantados em 1996, em espaçamento 3 × 2 m, com população de 1.666 mudas por hectare. Ambos os povoamentos possuem a mesma idade (13 anos), porém em ciclos de 
rotação distintos. Além disso, antes do florestamento, as duas áreas de estudo encontravam-se sob campo natural, favorecendo a avaliação da qualidade química do solo após a introdução da espécie $P$. taeda.

A coleta das amostras em cada área de estudo foi realizada através da abertura de trincheiras nas entrelinhas dos plantios da RT1 e RT2 e nas suas respectivas testemunhas: CN1 e CN2 (áreas de campo natural adjacentes). Desse modo, foram abertas cinco trincheiras com $0,60 \mathrm{~m}$ de profundidade, em cada área de estudo, totalizando 20 pontos de coleta, nas quais foram coletadas amostras com estrutura alterada, nas camadas $0,00-0,05 ; 0,05-0,20 ; 0,20-0,40$ e $0,40-0,60 \mathrm{~m}$.

\section{Análises físicas do solo}

A análise granulométrica foi feita pelo método da pipeta (EMBRAPA, 2011). Os dados da análise granulométrica (Tabela 1) permitem verificar que as duas áreas de estudo apresentaram textura argilosa nas camadas avaliadas.

Tabela 1. Frações granulométricas do Cambissolo Húmico e suas respectivas classes texturais para as áreas e camadas em estudo, em Cambará do Sul, RS, Brasil.

Table 1. Size fractions of Haplumbrept and their textural classes for the areas and layers, in Cambará do Sul, RS, Brazil.

\begin{tabular}{|c|c|c|c|c|c|c|}
\hline \multirow{2}{*}{$\begin{array}{c}\text { Camada } \\
(\mathbf{m})\end{array}$} & \multicolumn{3}{|c|}{ Areia $\left(\mathrm{g} \mathrm{kg}^{-1}\right)$} & \multirow{2}{*}{$\begin{array}{c}\text { Silte } \\
\left(\mathrm{g} \mathrm{kg}^{-1}\right)\end{array}$} & \multirow{2}{*}{$\begin{array}{l}\text { Argila } \\
\left(\mathrm{g} \mathrm{kg}^{-1}\right)\end{array}$} & \multirow{2}{*}{$\begin{array}{c}\text { Classe } \\
\text { textural }\end{array}$} \\
\hline & Total & Grossa & Fina & & & \\
\hline \multicolumn{7}{|c|}{ Área de $1^{\mathrm{a}}$ rotação de Pinus taeda } \\
\hline $0,00-0,05$ & 156 & 102 & 54 & 275 & 569 & Argilosa \\
\hline $0,05-0,20$ & 165 & 106 & 59 & 297 & 538 & Argilosa \\
\hline $0,20-0,40$ & 179 & 125 & 54 & 299 & 522 & Argilosa \\
\hline $0,40-0,60$ & 197 & 138 & 59 & 239 & 564 & Argilosa \\
\hline \multicolumn{7}{|c|}{ Campo natural adjacente à $1^{\text {a }}$ rotação } \\
\hline $0,00-0,05$ & 179 & 116 & 63 & 322 & 499 & Argilosa \\
\hline $0,05-0,20$ & 162 & 108 & 54 & 342 & 496 & Argilosa \\
\hline $0,20-0,40$ & 157 & 105 & 52 & 255 & 588 & Argilosa \\
\hline $0,40-0,60$ & 143 & 95 & 48 & 208 & 649 & Muito argilosa \\
\hline \multicolumn{7}{|c|}{ Área de $2^{\mathrm{a}}$ rotação de Pinus taeda } \\
\hline $0,00-0,05$ & 208 & 123 & 85 & 302 & 490 & Argilosa \\
\hline $0,05-0,20$ & 215 & 135 & 80 & 297 & 488 & Argilosa \\
\hline $0,20-0,40$ & 195 & 126 & 69 & 240 & 565 & Argilosa \\
\hline $0,40-0,60$ & 179 & 116 & 63 & 232 & 589 & Argilosa \\
\hline \multicolumn{7}{|c|}{ Campo natural adjacente à $2^{\mathrm{a}}$ rotação } \\
\hline $0,00-0,05$ & 175 & 104 & 71 & 308 & 517 & Argilosa \\
\hline $0,05-0,20$ & 170 & 106 & 64 & 329 & 501 & Argilosa \\
\hline $0,20-0,40$ & 192 & 124 & 68 & 263 & 545 & Argilosa \\
\hline $0,40-0,60$ & 155 & 86 & 69 & 269 & 576 & Argilosa \\
\hline
\end{tabular}

Análises químicas do solo

A determinação das propriedades químicas do solo foi realizada no Laboratório de Análise Química e Fertilidade do Solo da Universidade Federal de Santa Maria, conforme a metodologia descrita em Tedesco et al. (1995). Foram analisados cálcio trocável $(\mathrm{Ca})$, magnésio trocável $(\mathrm{Mg})$, potássio trocável $(\mathrm{K})$, alumínio trocável, $\mathrm{pH}$ em água, $\mathrm{pH}_{\mathrm{SMP}}$, fósforo disponível $(\mathrm{P})$, nitrogênio total e carbono orgânico total.

O cálcio e o magnésio foram extraídos em $\mathrm{KCl} 1 \mathrm{M}$ e determinados em espectrofotômetro de absorção atômica. O potássio e o fósforo foram obtidos pelo extrator Mehlich, sendo as leituras realizadas em espectrofotômetro de colorimetria e fotômetro de chamas, respectivamente.

$\mathrm{O}$ alumínio trocável foi obtido através da titulação de $\mathrm{NaOH}(0,0116 \mathrm{~N})$ em $\mathrm{KCl} 1 \mathrm{M} . \mathrm{O}$ pH em água na proporção 1:1 e o $\mathrm{pH}_{\mathrm{SMP}}$ foram quantificados através de phmetro.

O nitrogênio total e o carbono orgânico total foram determinados por oxidação via seca em analisador elementar. Nesse caso, a divisão dos dois deu origem à relação C/N. A matéria orgânica (MO) foi obtida pela percentagem de carbono orgânico total multiplicada por 1,724.

FLORESTA, Curitiba, PR, v. 45, n. 3, p. 455 - 464, jul. / set. 2015.

Abrão, S. F. et al.

ISSN eletrônico 1982-4688 / ISSN impresso 0015-3826

DOI: $10.5380 /$ rf.v45i3.36103 


\section{Análises estatísticas dos dados}

A estratégia de análise estatística foi comparar os dados referentes à RT1 e RT2 com suas respectivas testemunhas, CN1 e CN2. Para isso, os dados foram submetidos ao teste de Shapiro-Wilk, a fim de se verificar a normalidade da distribuição. Como os dados referentes às propriedades químicas não apresentaram distribuição normal, foram submetidos à transformação Box-Cox, sendo aplicado posteriormente o teste não paramétrico de Kruskal-Wallis, em 5\% de probabilidade de erro. Para verificar as relações entre as variáveis, realizou-se complementarmente a análise de coeficientes de correlação de Spearman.

\section{RESULTADOS E DISCUSSÃO}

\section{Cálcio e magnésio}

A análise dos teores de Ca entre a RT1 e o CN1 mostra que apenas na camada de 0,0-0,05 m houve diferença significativa, sendo maiores no CN1. Os teores de Ca entre a RT2 e o CN2 mostraram diferença significativa até a profundidade de $0,20 \mathrm{~m}$, sendo maiores no $\mathrm{CN} 2$ em relação à $\mathrm{RT} 2$, enquanto os teores de $\mathrm{Mg}$ mostraram diferença significativa apenas na camada superficial $(0,0-0,05 \mathrm{~m})$, onde tanto na RT1como na RT2 os valores foram inferiores, respectivamente, aos do CN1 e CN2 (Tabela 2).

Tabela 2. Atributos químicos do Cambissolo Húmico para as áreas e camadas em estudo, em Cambará do Sul, RS, Brasil.

Table 2. Haplumbrept chemical attributes for areas and layers, in Cambará do Sul, RS, Brazil.

\begin{tabular}{|c|c|c|c|c|c|c|c|}
\hline \multirow{2}{*}{ Área } & Al & Ca & Mg & $\mathbf{P}$ & K & \multirow{2}{*}{ pH } & \multirow{2}{*}{$\mathbf{p H}_{\mathrm{SMP}}$} \\
\hline & \multicolumn{3}{|c|}{ 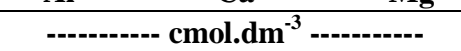 } & \multicolumn{2}{|c|}{---- mg.dm ${ }^{-3}$} & & \\
\hline \multicolumn{8}{|c|}{ Camada $0,0-0,05 \mathrm{~m}$} \\
\hline RT1 & $10,14 \mathrm{a}^{*}$ & $0,79 \mathrm{~b}$ & $0,68 \mathrm{~b}$ & $5,31 \mathrm{a}$ & $44,80 \mathrm{a}$ & $4,68 \mathrm{~b}$ & $4,09 \mathrm{~b}$ \\
\hline CN1 & $8,76 \mathrm{~b}$ & $1,39 \mathrm{a}$ & $1,00 \mathrm{a}$ & $2,99 \mathrm{~b}$ & $44,40 \mathrm{a}$ & $4,83 \mathrm{a}$ & $4,18 \mathrm{a}$ \\
\hline RT2 & $9,85 \mathrm{a}$ & $0,86 \mathrm{~b}$ & $0,28 \mathrm{~b}$ & $5,74 \mathrm{a}$ & $26,00 \mathrm{~b}$ & $4,25 \mathrm{~b}$ & $4,05 \mathrm{~b}$ \\
\hline $\mathrm{CN} 2$ & $5,67 \mathrm{~b}$ & $1,78 \mathrm{a}$ & $0,76 \mathrm{a}$ & $2,54 \mathrm{~b}$ & $96,40 \mathrm{a}$ & $4,86 \mathrm{a}$ & $4,42 \mathrm{a}$ \\
\hline \multicolumn{8}{|c|}{ Camada 0,05-0,20 m } \\
\hline RT1 & $10,06 \mathrm{a}$ & $0,72 \mathrm{a}$ & $0,52 \mathrm{a}$ & $2,48 \mathrm{a}$ & $28,00 \mathrm{a}$ & $4,56 \mathrm{~b}$ & $4,10 \mathrm{~b}$ \\
\hline CN1 & $8,83 \mathrm{~b}$ & $0,96 \mathrm{a}$ & $0,52 \mathrm{a}$ & $1,45 \mathrm{~b}$ & $22,40 \mathrm{a}$ & $4,87 \mathrm{a}$ & $4,19 \mathrm{a}$ \\
\hline RT2 & $10,02 \mathrm{a}$ & $0,76 \mathrm{~b}$ & $0,24 \mathrm{a}$ & $2,48 \mathrm{a}$ & $24,40 \mathrm{a}$ & $4,41 \mathrm{~b}$ & $4,06 \mathrm{~b}$ \\
\hline $\mathrm{CN} 2$ & $6,60 \mathrm{~b}$ & $1,05 \mathrm{a}$ & $0,40 \mathrm{a}$ & $1,64 \mathrm{a}$ & $44,00 \mathrm{a}$ & $4,80 \mathrm{a}$ & $4,34 \mathrm{a}$ \\
\hline \multicolumn{8}{|c|}{ Camada 0,20-0,40 m } \\
\hline RT1 & $9,42 \mathrm{a}$ & $0,72 \mathrm{a}$ & $0,40 \mathrm{a}$ & $0,79 \mathrm{a}$ & $17,20 \mathrm{a}$ & $4,87 \mathrm{~b}$ & $4,15 \mathrm{a}$ \\
\hline $\mathrm{CN} 1$ & $9,48 \mathrm{a}$ & $0,72 \mathrm{a}$ & $0,36 \mathrm{a}$ & $0,89 \mathrm{a}$ & $16,40 \mathrm{a}$ & $5,00 \mathrm{a}$ & $4,21 \mathrm{a}$ \\
\hline RT2 & $8,93 \mathrm{a}$ & $1,08 \mathrm{a}$ & $0,36 \mathrm{a}$ & $2,54 \mathrm{a}$ & $41,60 \mathrm{a}$ & $4,69 \mathrm{~b}$ & $4,20 \mathrm{a}$ \\
\hline $\mathrm{CN} 2$ & $6,69 \mathrm{a}$ & $0,84 \mathrm{a}$ & $0,32 \mathrm{a}$ & $0,99 \mathrm{a}$ & $30,80 \mathrm{a}$ & $4,94 \mathrm{a}$ & $4,36 \mathrm{a}$ \\
\hline \multicolumn{8}{|c|}{ Camada 0,40-0,60 m } \\
\hline RT1 & $9,19 \mathrm{a}$ & $0,67 \mathrm{a}$ & $0,24 \mathrm{a}$ & $0,64 \mathrm{a}$ & $13,60 \mathrm{a}$ & $4,94 \mathrm{~b}$ & $4,22 \mathrm{a}$ \\
\hline CN1 & $9,21 \mathrm{a}$ & $0,79 \mathrm{a}$ & $0,32 \mathrm{a}$ & $0,53 \mathrm{a}$ & $14,80 \mathrm{a}$ & $5,09 \mathrm{a}$ & $4,19 \mathrm{a}$ \\
\hline RT2 & $10,72 \mathrm{a}$ & $0,74 \mathrm{a}$ & $0,24 \mathrm{a}$ & $1,16 \mathrm{a}$ & $22,80 \mathrm{a}$ & $4,70 \mathrm{~b}$ & $4,11 \mathrm{a}$ \\
\hline $\mathrm{CN} 2$ & $6,71 b$ & $0,89 \mathrm{a}$ & $0,28 \mathrm{a}$ & $0,64 \mathrm{a}$ & $20,00 \mathrm{a}$ & $5,06 \mathrm{a}$ & $4,36 \mathrm{a}$ \\
\hline
\end{tabular}

RT1: área de estudo de $1^{\mathrm{a}}$ rotação; CN1: campo natural adjacente à RT1; RT2: área de estudo de $2^{\mathrm{a}}$ rotação; CN2: campo natural adjacente à RT2. * : Médias não seguidas por mesma letra diferem entre si pelo teste de Kruskal-Wallis em 5\% de probabilidade de erro.

Esses resultados evidenciam que a conversão do campo natural em área florestada com $P$. taeda alterou os teores de $\mathrm{Ca}$ e $\mathrm{Mg}$, os quais foram reduzidos nas camadas mais superficiais do solo. Os teores de $\mathrm{Ca}$ encontrados neste trabalho são considerados baixos $\left(\leq 2 \mathrm{cmol}_{\mathrm{c}} \cdot \mathrm{dm}^{-3}\right)$ pela Sociedade Brasileira de Ciência do Solo (SBCS, 2004), assim como os valores de Mg também são considerados baixos $\left(\leq 0,5 \mathrm{cmol}_{\mathrm{c}} \cdot \mathrm{dm}^{-3}\right)$, sendo alguns valores classificados como médios $\left(0,6-1,0 \mathrm{cmol}_{\mathrm{c}} \cdot \mathrm{dm}^{-3}\right)$. Cabe ressalvar que os Cambissolos Húmicos dessa região apresentam naturalmente baixos teores de Ca e Mg (BRASIL, 1973).

Os menores teores de Ca e de Mg observados nas áreas com P. taeda na RT1 e RT2 podem estar relacionados à lixiviação e à absorção desses elementos pelo elevado número de raízes finas presentes nas 
camadas mais superficiais do solo (JANDL et al., 2004), bem como ao acúmulo desses nutrientes na biomassa florestal (RICHTER et al., 1994). Reissmann e Wisnewski (2005) relatam que, na serapilheira, ficam armazenadas grandes quantidades de nutrientes, sendo que parte deles pode permanecer imobilizado se a decomposição da biomassa for muito lenta. Em contrapartida, os nutrientes que são mineralizados podem ser reabsorvidos pelas raízes finas que permeiam a serapilheira acumulada ou serem lixiviados pela água da chuva.

$\mathrm{Na}$ mesma região do presente estudo, Ca foi o macronutriente de maior teor médio encontrado na serapilheira $\left(6,62 \mathrm{~g}_{\mathrm{kg}}{ }^{-1}\right.$.ano), composta por acículas de um povoamento de $P$. taeda, em área de segunda rotação (SCHUMACHER et al., 2008). Para os autores, esse nutriente foi o mais fornecido em quantidade ao piso florestal (28,7 kg.ha ${ }^{-1}$ ano) e, considerando a transferência de $\mathrm{Ca}+\mathrm{N}$, isso corresponde a mais de $80 \%$ do total de macronutrientes retornados ao solo. No entanto, o Ca, depois de absorvido e transportado para as folhas, se torna imóvel, pois a maior parte encontrada nos tecidos vegetais permanece sob formas não solúveis em água e sais cálcicos de baixa solubilidade (DECHEN; NACHTIGALL, 2007).

Dessa forma, a retenção do $\mathrm{Ca}$ associada à baixa taxa de decomposição da biomassa pode agravar ainda mais os problemas nutricionais do Cambissolo Húmico, o que representa uma ruptura no processo de ciclagem de nutrientes. Resultados semelhantes foram reportados por Mafra et al. (2008), os quais encontraram, na camada $0,0-0,5 \mathrm{~m}$, teores de $\mathrm{Ca}$ e $\mathrm{Mg}$ maiores em campo nativo quando comparados a povoamentos de P. taeda com 12 e 20 anos de idade. No mesmo estudo, as áreas com pínus foram as que apresentaram os menores teores dentre todas as coberturas florestais avaliadas (floresta nativa e reflorestamento de araucária). Quando se compararam solos sob povoamentos antigos de Pinus silvestris L., povoamentos jovens e áreas cultivadas, os teores de cátions trocáveis e a saturação por bases foram menores na área florestada há mais tempo, apresentando declínio nos teores de $\mathrm{Ca}, \mathrm{Mg}$ e $\mathrm{K}$, sugerindo que eles foram substituídos por íons $\mathrm{H}^{+}$, refletindo em aumento da acidez do solo (OLSZEWSKA; SMAL, 2008).

\section{Fósforo e potássio}

Os teores de P da RT1 e CN1 mostram valores superiores na RT1 até a profundidade de $0,20 \mathrm{~m}$. Nas demais camadas não houve diferença significativa (Tabela 2). Em RT2 e CN2, observou-se o mesmo comportamento, mas diferindo significativamente apenas na camada $0,0-0,05 \mathrm{~m}$. Os teores de $\mathrm{K}$ não apresentaram diferenças significativas entre RT1 e CN1 em nenhuma das camadas (Tabela 2). Entre a RT2 e o CN2, houve diferença apenas na camada 0,0-0,05 m, sendo os teores de K maiores no CN2.

De acordo com a SBCS (2004), os dados referentes aos teores de P disponíveis foram, em geral, muito baixos ( $\left.\leq 3 \mathrm{mg} \cdot \mathrm{dm}^{-3}\right)$, com exceção das camadas mais superficiais de RT1 e RT2, que apresentaram valores um pouco mais elevados, classificando-se como baixos. Esse resultado já era esperado, devido à pouca disponibilidade desse nutriente no solo da região, em consequência da elevada acidez do solo (SCHUMACHER et al., 2008), pois valores de $\mathrm{pH}$ abaixo de 5,5 são geralmente associados a reduções na disponibilidade de fósforo, como mostra a correlação entre essas variáveis nas tabelas 3 e 4 . Porém, como as plantas absorvem a maior parte do $\mathrm{P}$ como ânion monovalente $\left(\mathrm{H}_{2} \mathrm{PO}_{4}{ }^{-}\right)$, esse nutriente não tem sua disponibilidade prejudicada em valores de pH abaixo de 7,0 (DECHEN; NACHTIGALL, 2007).

Tabela 3. Coeficientes de correlação de Spearman entre variáveis encontradas na primeira área de estudo. Table 3. Spearman's correlation coefficients between variables found in the first study area.

\begin{tabular}{|c|c|c|c|c|c|c|c|c|c|c|}
\hline Variável & $\mathrm{Ca}$ & $\mathbf{M g}$ & $\mathbf{K}$ & $\mathbf{P}$ & Al & pH & $\mathbf{p H}_{\mathrm{SMP}}$ & CTCef & CTCph7 & M.O. \\
\hline $\mathrm{Ca}$ & 1,00 & $0,59^{* *}$ & $0,40^{*}$ & $0,32^{*}$ & $-0,28$ & $-0,13$ & 0,01 & 0,23 & $0,32^{*}$ & $0,53^{* *}$ \\
\hline $\mathrm{Mg}$ & & 1,00 & $0,82^{* *}$ & $0,82^{* * *}$ & 0,10 & $-0,51$ & $-0,42^{* * *}$ & $0,58^{* *}$ & $0,70^{* *}$ & $0,85^{* *}$ \\
\hline $\mathrm{K}$ & & & 1,00 & $0,91^{* *}$ & 0,08 & $-0,64$ & $-0,48^{* *}$ & $0,48^{* *}$ & $0,69^{* * *}$ & $0,83^{* *}$ \\
\hline $\mathrm{P}$ & & & & 1,00 & 0,23 & $-0,71^{* * *}$ & $-0,56^{* *}$ & $0,56^{* *}$ & $0,72^{* * *}$ & $0,81^{* *}$ \\
\hline $\mathrm{Al}$ & & & & & 1,00 & $-0,22$ & $-0,66^{* *}$ & $0,79^{* *}$ & $0,49^{* * *}$ & $-0,01$ \\
\hline $\mathrm{pH}$ & & & & & & 1,00 & $0,64^{* *}$ & $-0,35^{*}$ & $-0,67^{* *}$ & $-0,66^{* *}$ \\
\hline $\mathrm{pH}_{\mathrm{SMP}}$ & & & & & & & 1,00 & $-0,65^{* * *}$ & $-0,91^{* * *}$ & $-0,46^{* *}$ \\
\hline CTCef & & & & & & & & 1,00 & $0,73^{* *}$ & $0,46^{* *}$ \\
\hline CTCph7 & & & & & & & & & 1,00 & $0,69^{* *}$ \\
\hline MO & & & & & & & & & & 1,00 \\
\hline
\end{tabular}

${ }^{\pi *}$ : correlação RT1 x CN1 significativa a 1\% de probabilidade de erro. * : correlação RT1 x CN1 significativa a 5\% de probabilidade de erro. 
Tabela 4. Coeficientes de correlação de Spearman entre variáveis encontradas na segunda área de estudo. Table 4. Spearman's correlation coefficients between variables found in the second study area.

\begin{tabular}{|c|c|c|c|c|c|c|c|c|c|c|}
\hline Variável & $\mathrm{Ca}$ & Mg & $\mathbf{K}$ & $\mathbf{P}$ & Al & pH & $\mathbf{p H}_{\text {SMP }}$ & CTCef & CTCph7 & M.O. \\
\hline $\mathrm{Ca}$ & 1,00 & $0,82^{* * *}$ & $0,62^{* *}$ & $0,46^{* *}$ & $-0,60^{* *}$ & $0,37^{*}$ & $0,51^{* *}$ & $-0,33^{*}$ & $-0,31^{*}$ & $0,36^{*}$ \\
\hline $\mathrm{Mg}$ & & 1,00 & $0,67^{* *}$ & $0,47^{* *}$ & $-0,58^{* *}$ & 0,22 & $0,50^{* *}$ & $-0,27$ & $-0,27$ & $0,40^{*}$ \\
\hline K & & & 1,00 & $0,62^{* *}$ & $-0,41^{* *}$ & $-0,00$ & $0,34^{*}$ & $-0,15$ & $-0,15$ & $0,46^{* *}$ \\
\hline$P$ & & & & 1,00 & $-0,22$ & $-0,36^{*}$ & 0,06 & 0,11 & 0,17 & $0,86^{* *}$ \\
\hline $\mathrm{Al}$ & & & & & 1,00 & $-0,65^{* *}$ & $-0,89^{* *}$ & $0,87^{* *}$ & $0,79^{* *}$ & $-0,17$ \\
\hline $\mathrm{pH}$ & & & & & & 1,00 & $0,76^{* *}$ & $-0,72^{* *}$ & $-0,81^{* *}$ & $-0,38^{*}$ \\
\hline $\mathrm{pH}_{\mathrm{SMP}}$ & & & & & & & 1,00 & $-0,81^{* *}$ & $-0,93^{* *}$ & $-0,00$ \\
\hline CTCef & & & & & & & & 1,00 & $0,89^{* *}$ & 0,10 \\
\hline CTCph7 & & & & & & & & & 1,00 & 0,19 \\
\hline MO & & & & & & & & & & 1,00 \\
\hline
\end{tabular}

*** correlação RT2 x CN2 significativa a $1 \%$ de probabilidade de erro. * : correlação RT2 x CN2 significativa a $5 \%$ de probabilidade de erro.

Os teores de $\mathrm{P}$ encontrados, apesar de serem considerados baixos, foram maiores nas áreas com plantios de $P$. taeda em relação às áreas de campo natural. Isso indica que o cultivo de pínus não reduziu $\mathrm{o}$ teor de $\mathrm{P}$ nas camadas superficiais, tendo em vista os maiores teores encontrados na RT2. De acordo com Chaves e Corrêa (2005), o pínus, por ser pouco exigente em P e K, não deve ser uma espécie causadora de desequilíbrios desses nutrientes no solo em longo prazo. Esse resultado pode ser verificado pelo maior teor de P observado na camada superficial de RT1 e RT2, esta última representando aproximadamente 30 anos de uso do solo com florestamento de pínus.

Os baixos valores encontrados nos teores de P podem guardar relação com os baixos valores de $\mathrm{pH}$, que controlam, de certa forma, a forma pela qual o P é retido (CHAVES; CORRÊA, 2005). Assim, em solos ácidos ricos em óxidos de $\mathrm{Fe}$ e Al, o fósforo da solução do solo tende a formar fosfato de ferro e de alumínio (altamente insolúveis), mantendo fixadas grandes proporções de fósforo total no solo.

Resultados semelhantes foram encontrados avaliando-se as propriedades químicas de um solo com diferentes coberturas florestais, em que o solo sob P. taeda, com 20 anos de idade, apresentou maiores teores de $\mathrm{P}$ disponível até a camada de $0,20 \mathrm{~m}$. $\mathrm{O}$ resultado foi relacionado à absorção diferenciada de $\mathrm{P}$ pelo pínus e, ainda, à influência de fungos micorrízicos, que ocorrem naturalmente na área e modificam a conformação do sistema radicular e a habilidade da planta de aproveitar esse elemento em solo com baixos teores de P (MAFRA et al., 2008).

Os teores encontrados de K foram muito variados. De modo geral, foram classificados, conforme a SBCS (2004), como muito baixos $\left(\leq 30 \mathrm{mg} \cdot \mathrm{dm}^{-3}\right)$. No entanto, houve teores entre $31 \mathrm{e} 60 \mathrm{mg} \cdot \mathrm{dm}^{-3}$, considerados baixos, e, na camada $0,0-0,05 \mathrm{~m}$ do $\mathrm{CN} 2$, o teor de $\mathrm{K}$ foi classificado como alto. Observouse, ainda, com exceção da camada 0,20-0,40 m da RT2, que os teores de K do solo decresceram em profundidade. Esse comportamento pode estar associado à maior presença dos constituintes orgânicos nas camadas superficiais, conforme evidenciado na correlação entre as variáveis (Tabelas 3 e 4). Ressalte-se, ainda, a contribuição da matéria orgânica no aumento de cargas negativas do solo, alterando a distribuição do K no perfil e evitando perdas desse nutriente pela lixiviação no solo. O mesmo comportamento foi relatado por Mafra et al. (2008).

Ao longo de três décadas monitorando uma floresta de $P$. taeda, mesmo período do presente estudo, foi observado que o teor de $\mathrm{K}$ permaneceu relativamente constante ao longo do tempo, com reduções pequenas até a camada de $0,15 \mathrm{~m}$ (RICHTER et al., 1994). O resultado foi atribuído à combinação da liberação de $\mathrm{K}$ por intemperismo mineral, absorção radicular e ciclagem rápida à superfície dos solos por meio da lixiviação do dossel e do piso florestal.

\section{Alumínio trocável e pH do solo}

Os teores de Al foram, até a profundidade $0,20 \mathrm{~m}$, superiores na RT1 e RT2, respectivamente, em relação ao CN1 e CN2, à exceção da camada $0,40-0,60 \mathrm{~m}$ da RT2, que apresentou valor superior ao CN2 (Tabela 2). Os teores de Al trocável variaram entre 5,67 e $10,14 \mathrm{cmol}_{c} \cdot \mathrm{dm}^{-3}$, sendo considerados teores elevados (BRASIL, 1973), justificados pelos baixos valores de $\mathrm{pH}$, favorecendo a solubilização do Al trocável no solo, como demonstrado pela alta correlação (Tabela 3 e 4). 
Os valores de pH do solo ou acidez ativa (Tabela 2) foram menores na RT1 e RT2 em comparação ao respectivo CN1 e CN2, em todas as camadas avaliadas. De modo geral, nas duas áreas de estudo, os valores de $\mathrm{pH}$ foram muito baixos, fato já esperado devido aos Cambissolos Húmicos serem fortemente ácidos, com pH variando de 4,5 a 5,0 ao longo do perfil (BRASIL, 1973). No entanto, a maior acidificação do solo observada nas áreas com plantios de pínus é comum em locais que apresentam essa atividade, devido à lixiviação de bases e absorção de elementos pelas árvores (MAFRA et al., 2008).

Além disso, a acidez observada pode estar relacionada ao aporte de serapilheira formada principalmente por acículas, que apresentam altos teores de alumínio (BRUM, 1980). A acidificação pode ser atribuída também à entrada de ácidos orgânicos provenientes da lixiviação desse material, promovendo maior respiração no solo, nitrificação e perdas de nitrato (WIESMEIER et al., 2009). Dessa forma, os ácidos orgânicos produzidos pela decomposição da serapilheira atuam no sentido de favorecer o processo de intemperismo e acidez do solo, pois alguns produtos da decomposição da matéria orgânica podem agir como agentes quelantes, facilitando a hidrólise do alumínio e, portanto, liberando íons $\mathrm{H}^{+} \mathrm{e}$ reduzindo o $\mathrm{pH}$ do solo, o que contribui com o poder tampão do solo. Resultados semelhantes foram evidenciados por Lepsch (1980) e Mafra et al. (2008).

A acidez potencial $\left(\mathrm{pH}_{\mathrm{SMP}}\right)$, nas duas áreas de estudo, diferiu significativamente até a camada de 0,20 m (Tabela 2), apresentando valores maiores nas áreas de campo natural e, consequentemente, menor acidez. Esse resultado deve-se ao fato de que os elevados teores de alumínio trocável e de matéria orgânica ocorrem nessas camadas, principalmente nas áreas com plantios de pínus, exigindo maiores quantidades de carbonatos para sua correção, evidenciando o alto poder de tamponamento dos Cambissolos Húmicos.

Em suma, o P. taeda alterou significativamente os teores de alumínio trocável e a acidez do solo, elevando os teores de $\mathrm{Al}$ e reduzindo o $\mathrm{pH}$, principalmente até a camada de $0,20 \mathrm{~m}$, sugerindo, por meio desses atributos químicos, a influência na redução de outros nutrientes, conforme se observa na correlação entre a capacidade de troca e o pH do solo (Tabelas 3 e 4), que refletiu numa diminuição da qualidade química do Cambissolo Húmico.

\section{Nitrogênio total e carbono orgânico total}

Quanto aos teores de nitrogênio total (N), na camada de 0,0-0,05 m, a RT1 apresentou teor inferior ao CN1, e na camada de 0,2-0,40 m, valor superior. Nas demais camadas não houve diferenças significativas (Tabela 5). Na RT2 em relação ao CN2, houve diferença significativa apenas na camada de 0,05-0,20 m, com valor inferior para a RT2.

O carbono orgânico (C) mostrou o mesmo comportamento do $\mathrm{N}$ : na camada de 0,0-0,05 m, a RT1 apresentou teor inferior ao CN1, e na camada de 0,2-0,40 m, valor superior (Tabela 5). A RT2 apresentou teor inferior em relação ao CN2 na camada de $0,05-0,20 \mathrm{~m}$ e superior na de $0,40-0,60 \mathrm{~m}$. Nas demais camadas não houve diferenças significativas. O comportamento do teor de matéria orgânica (MO) foi semelhante ao do $\mathrm{C}$, visto que a MO é obtida pela percentagem de $\mathrm{C}$ multiplicada por uma constante de 1,724. A relação $\mathrm{C} / \mathrm{N}$ não diferiu nas duas áreas e camadas avaliadas (Tabela 5).

Na camada superficial (0,0-0,05 m), o CN1 apresentou maior teor de C em relação a RT1. Esse resultado pode estar relacionado ao fato de as raízes das gramíneas serem anualmente renovadas, proporcionando maior incorporação do C no horizonte superficial do campo nativo (LEPSCH, 1980). Porém o mesmo autor afirma que, nos florestamentos, a matéria orgânica incorporada à camada mineral superficial do solo em pouco tempo tende a atingir quantidade em equilíbrio com as condições do ambiente, confirmando a relação entre o conteúdo de carbono e a idade do florestamento (BOCHNER et al., 2008; FACHINI, 2012).

Portanto, deve ser considerada a composição da serapilheira depositada na superfície do solo, a qual apresenta decomposição e incorporação mais lenta se comparada ao material orgânico fornecido pelas gramíneas, contribuindo para os menores valores de $\mathrm{C}$ e $\mathrm{N}$ encontrados no povoamento de pínus (WIESMEIER et al., 2009). Nesse caso, os autores também associaram a redução do $\mathrm{N}$ à absorção desse elemento e imobilização na biomassa acima do solo, já que o $\mathrm{N}$ é um dos macronutrientes que concentram maiores teores nas acículas em distintos estádios fenológicos (VIERA; SCHUMACHER, 2009). Logo, a manutenção de resíduos vegetais tem uma contribuição fundamental para a ciclagem de nutrientes e manutenção da fertilidade do solo em sistemas florestais ou agroflorestais (REICHERT et al., 2015).

FLORESTA, Curitiba, PR, v. 45, n. 3, p. 455 - 464, jul. / set. 2015.

Abrão, S. F. et al.

ISSN eletrônico 1982-4688 / ISSN impresso 0015-3826

461

DOI: $10.5380 /$ rf.v45i3.36103 
Tabela 5. Nitrogênio total, carbono orgânico total, matéria orgânica e relação $\mathrm{C} / \mathrm{N}$ do Cambissolo Húmico para as áreas e camadas em estudo, em Cambará do Sul, RS, Brasil.

Table 5. Total nitrogen, total organic carbon, organic matter and $\mathrm{C} / \mathrm{N}$ ratio of Haplumbrept for areas and layers, in Cambará do Sul, RS, Brazil.

\begin{tabular}{|c|c|c|c|c|}
\hline Área & Nitrogênio total & Carbono orgânico total & Matéria orgânica & $\mathrm{C} / \mathrm{N}$ \\
\hline \multicolumn{5}{|c|}{ Camada $0,00-0,05 \mathrm{~m}$} \\
\hline RT1 & $2,28 b^{*}$ & $39,1 \mathrm{~b}$ & $67,4 \mathrm{~b}$ & $17,1 \mathrm{a}$ \\
\hline $\mathrm{CN} 1$ & $2,96 \mathrm{a}$ & $49,9 \mathrm{a}$ & $86,0 \mathrm{a}$ & $16,9 \mathrm{a}$ \\
\hline RT2 & $3,11 \mathrm{a}$ & $47,6 \mathrm{a}$ & $82,0 \mathrm{a}$ & $15,3 \mathrm{a}$ \\
\hline $\mathrm{CN} 2$ & $3,00 \mathrm{a}$ & $40,6 \mathrm{a}$ & $70,1 \mathrm{a}$ & $13,5 \mathrm{a}$ \\
\hline \multicolumn{5}{|c|}{ Camada 0,05-0,20 m } \\
\hline RT1 & $2,17 \mathrm{a}$ & $37,6 \mathrm{a}$ & 64,8 a & $17,3 \mathrm{a}$ \\
\hline $\mathrm{CN} 1$ & $2,10 \mathrm{a}$ & 37,6 a & $64,8 \mathrm{a}$ & $17,9 \mathrm{a}$ \\
\hline RT2 & $1,79 \mathrm{~b}$ & $27,2 \mathrm{~b}$ & $46,9 \mathrm{~b}$ & $15,2 \mathrm{a}$ \\
\hline $\mathrm{CN} 2$ & $2,14 \mathrm{a}$ & $32,1 \mathrm{a}$ & $55,4 \mathrm{a}$ & $15,0 \mathrm{a}$ \\
\hline \multicolumn{5}{|c|}{ Camada 0,20-0,40 m } \\
\hline RT1 & $1,50 \mathrm{a}$ & $26,7 \mathrm{a}$ & $46,0 \mathrm{a}$ & $17,8 \mathrm{a}$ \\
\hline $\mathrm{CN} 1$ & $1,33 \mathrm{~b}$ & $23,1 \mathrm{~b}$ & $39,8 \mathrm{~b}$ & $17,4 \mathrm{a}$ \\
\hline RT2 & $1,91 \mathrm{a}$ & $27,9 \mathrm{a}$ & $48,2 \mathrm{a}$ & $14,6 \mathrm{a}$ \\
\hline $\mathrm{CN} 2$ & $1,41 \mathrm{a}$ & $23,6 \mathrm{a}$ & $40,6 \mathrm{a}$ & $16,7 \mathrm{a}$ \\
\hline \multicolumn{5}{|c|}{ Camada 0,40- 0,60 m } \\
\hline RT1 & $1,03 \mathrm{a}$ & $17,9 \mathrm{a}$ & $30,9 \mathrm{a}$ & $17,4 \mathrm{a}$ \\
\hline $\mathrm{CN} 1$ & $1,02 \mathrm{a}$ & $17,0 \mathrm{a}$ & $29,3 \mathrm{a}$ & $16,7 \mathrm{a}$ \\
\hline RT2 & $1,15 \mathrm{a}$ & $20,0 \mathrm{a}$ & 34,4 a & $17,4 \mathrm{a}$ \\
\hline $\mathrm{CN} 2$ & $0,97 \mathrm{a}$ & $16,9 \mathrm{~b}$ & $29,2 \mathrm{~b}$ & $17,4 \mathrm{a}$ \\
\hline
\end{tabular}

RT1: área de estudo de $1^{\mathrm{a}}$ rotação; CN1: campo natural adjacente à RT1; RT2: área de estudo de $2^{\mathrm{a}}$ rotação; CN2: campo natural adjacente à RT2. ": Médias não seguidas por mesma letra diferem entre si pelo teste de Kruskal-Wallis em 5\% de probabilidade de erro.

Ao analisarmos os dados conjuntos de RT2 e CN2, verifica-se que, na camada superficial (0,0$0,05 \mathrm{~m}$ ), os teores de C e N da RT2 são estatisticamente semelhantes aos teores encontrados no CN2. A remoção da floresta, a queima dos resíduos vegetais e o excessivo revolvimento do solo causam diminuição do aporte e aumento da degradação da MO, desestabilizando a estrutura do solo. No entanto, foram encontrados maiores teores de $\mathrm{C}$ em plantios com pínus, onde a biomassa havia sido queimada, demonstrando que os danos promovidos pela queima e/ou retirada da biomassa são contrabalançados pelo significativo aporte de serapilheira pelos povoamentos plantados (BRUN, 2008). O povoamento com pínus tem se mostrado eficiente na manutenção do estoque de carbono total do solo, bem como tende a aumentar na superfície do mesmo (COSTA LIMA et al., 1995).

Em suma, a substituição do campo natural por povoamentos de $P$. taeda alterou os atributos químicos avaliados, em que o plantio tendeu a diminuir os teores de $\mathrm{C}$ e $\mathrm{N}$ apenas na camada mais superficial do Cambissolo Húmico. No entanto, esse comportamento muda na segunda rotação, em que a área com plantio mantém-se semelhante ao campo natural nessa camada. Isso permite inferir, em longo prazo, que o povoamento de $P$. taeda é capaz de manter no solo níveis de $\mathrm{C}$ e $\mathrm{N}$ similares aos do campo original, pois é possível que os teores mais baixos vistos na camada seguinte estejam relacionados ao manejo adotado na área.

\section{CONCLUSÕES}

- Os atributos químicos do Cambissolo Húmico foram alterados com a mudança de uso (de campo natural para povoamento com pínus), com redução nas bases trocáveis $(\mathrm{Ca}$ e $\mathrm{Mg}$ ) nas camadas superficiais, mostrando que o intemperismo mineral e a ciclagem biológica possivelmente não foram capazes de manter o ritmo de reposição conforme ocorria a remoção desses nutrientes no solo.

- Os teores de $\mathrm{P}$ disponível e $\mathrm{Al}$ trocável aumentaram e o pH diminuiu nas áreas com povoamento. Os teores de $\mathrm{C}$ e $\mathrm{N}$ diminuíram na camada mais superficial do solo, mas esse comportamento muda na segunda rotação, em que a área com plantio manteve níveis de $\mathrm{C}$ e $\mathrm{N}$ similares aos do campo original. 
- As alterações nos atributos químicos foram mais pronunciadas na camada superficial, demonstrando a importância da biomassa acima do solo na ciclagem dos nutrientes, não se descartando a possibilidade de correção e fertilização do solo para garantir a manutenção da produtividade dos sítios ao longo das rotações.

\section{REFERÊNCIAS}

BOCHNER, J. K.; FERNANDES, M. M.; PEREIRA, M. G., BALIEIRO, F. C.; SANTANA, I. K. S. Matéria orgânica e agregação de um Planossolo sob diferentes coberturas florestais. Cerne, Lavras, v. 14, n. 1 , p. $46-53,2008$.

BOLDRINI, I. I.; EGGERS, L.; MENTZ, L. A.; MIOTTO, S. T. S.; MATZENBACHER, N. I.; LONGHIWAGNER, H. M.; TREVISAN, R.; SCHNEIDER, A. A.; SETÚBAL, R. B. Flora. In: BOLDRINI, I. I. Biodiversidade dos campos do planalto das araucárias. Brasília: MMA, 2009. p. 39 - 94.

BRASIL. Ministério da Agricultura. Departamento Nacional de Pesquisa Agropecuária. Divisão pedológica. Levantamento de reconhecimento dos solos do Estado do Rio Grande do Sul. Recife, 1973. 413 p. (DNPEA. Boletim técnico, 30).

BRUM, E. Composição química de acículas verdes e da liteira de Pinus elliotti Engelm. Revista Floresta, Curitiba, v. 11, n. 1, p. 17 - 23, 1980.

BRUN, E. J. Matéria orgânica do solo em plantios de Pinus taeda e P. elliottii em duas regiões do Rio Grande do Sul. 118 f. Tese (Doutorado em Engenharia Florestal) - Universidade Federal de Santa Maria, Santa Maria, 2008.

CHAVES, R. Q.; CORRÊA, G. F. Macronutrientes no sistema solo-Pinus caribaea Morelet em plantios apresentando amarelecimento das acículas e morte de plantas. Revista Árvore, Viçosa, v. 29, n. 5, p. 691 - 700, 2005.

COSTA LIMA, V.; LIMA, J. M. J. C.; CERRI, C. C.; FRANZON, J. F. Efeito da substituição de campo natural por Pinus na dinâmica do carbono do solo. Revista do Setor de Ciências Agrárias, Curitiba, v. 14, n. 1-2, p. 7 - 12, 1995.

DECHEN, A. R.; NACHTIGALL, G. R. Elementos requeridos à nutrição de plantas. In: NOVAIS, R. F; ALVAREZ V. V. H.; BARROS, N. F; FONTES, R. L. F; CANTARUTTI, R. B.; NEVES, J. C. L (Eds.). Fertilidade do solo. Viçosa: SBCS/UFV, 2007. p. 92 - 132.

EMPRESA BRASILEIRA DE PESQUISA AGROPECUÁRIA (EMBRAPA). Centro Nacional de Pesquisa de Solos. Sistema brasileiro de classificação de solos. 3. ed. Brasília: Embrapa Solos, 2013. $353 \mathrm{p}$.

EMPRESA BRASILEIRA DE PESQUISA AGROPECUÁRIA (EMBRAPA). Centro Nacional de Pesquisa de Solos. Manual de métodos de análise de solo. 2. ed. Rio de Janeiro: Embrapa Solos, 2011. 230 p.

FACHINI, L. Frações e estoques de carbono orgânico em solo do planalto catarinense cultivado com pinus. 49 f. Dissertação (Mestrado em Manejo do Solo) - Universidade do Estado de Santa Catarina, Lages, 2012.

JANDL, R.; ALEWELL, C.; PRIETZEL, J. Calcium loss in Central European forest soils. Soil Science Society of America Journal, Madison, v. 68, n. 2, p. 588 - 595, 2004.

LEPSCH, I. F. Influência do cultivo de Eucalyptus e Pinus nas propriedades químicas de solos sob cerrado. Revista Brasileira de Ciência do Solo, Campinas, v. 4, n. 2, p. 103 - 107, 1980.

MAFRA, A. L.; GUEDES, S. F. F.; FILHO, O. K.; SANTOS, J. C. P.; ALMEIDA, J. A.; ROSA, J. D. Carbono orgânico e atributos químicos do solo em áreas florestais. Revista Árvore, Viçosa, v. 32, n. 2, p. 217 - 224, 2008.

OLSZEWSKA, M.; SMAL, H. The effect of afforestation with Scots pine (Pinus silvestris L.) of sandy post-arable soils on their selected properties. I. Physical and sorptive properties. Plant Soil, Amsterdan, v. 305, n. 1-2, p. $157-169,2008$.

FLORESTA, Curitiba, PR, v. 45, n. 3, p. 455 - 464, jul. / set. 2015. 
REICHERT, J. M.; RODRIGUES, M. F.; BERVALD, C. M. P.; BRUNETTO, G.; KATO, O. R., SCHUMACHER, M. V. 2015. Fragmentation, fiber separation, decomposition, and nutrient release of secondary-forest biomass, mechanically chopped-and-mulched, and cassava production in the Amazon. Agriculture, Ecosystems \& Environmental, Amsterdam, in press.

REISSMANN, C. B.; WISNIEWSKI, C. Nutritional aspects of pine plantations. In: GONÇALVES, J. L. M.; BENEDETTI, V. Nutrition and forest fertilization. Piracicaba: IPEF, 2005. p. 135 - 166.

RICHTER, D. D.; MARKEWITZ, D.; WELlS, C. G.; ALLEN, H. L.; APRIL, R.; HEINE, P. R.; URREGO, B. Soil chemical change during three decades in an old-field loblolly pine (Pinus taeda L.) ecosystem. Ecology, Ithaca, v. 75, n. 5, p. 1463 - 1473, 1994.

SCHUMACHER. M. V.; VIERA, M.; WITSCHORECK, R. Produção de serapilheira e transferência de nutrientes em área de segunda rotação com floresta de Pinus taeda L. no município de Cambará do Sul, RS. Ciência Florestal, Santa Maria, v. 18, n. 4, p. 471 - 480, 2008.

SOCIEDADE BRASILEIRA DE CIÊNCIA DO SOLO (SBCS). Comissão de Química e Fertilidade do Solo. Manual de adubação e de calagem para os Estados do Rio Grande do Sul e de Santa Catarina. 10. ed. Porto Alegre: SBCS/CQFS, 2004. 400 p.

TEDESCO, M. J.; GIANELlO, C.; BISSANI, C. A.; BOHNEN, H.; VOLKWEISS, S. J. Análise de solo, plantas e outros materiais. 2. ed. Porto Alegre: Departamento de Solos: UFRGS, 1995. 174 p.

VIERA, M.; SCHUMACHER, M. V. Concentração e retranslocação de nutrientes em acículas de Pinus taeda L. Ciência Florestal, Santa Maria, v. 19, n. 4, p. 375 - 382, 2009.

WENDLING, B.; VINHAL-FREITAS, I. C.; OLIVEIRA, R. C.; BABATA, M. M.; BORGES, E. N. Densidade, agregação e porosidade do solo em áreas de conversão do cerrado em floresta de pínus, pastagem e plantio direto. Bioscience Journal, Uberlândia, v. 28, Supplement 1, p. 256 - 265, 2012.

WIESMEIER, M.; DICK, D. P.; RUMPEL, C.; DALMOLIN, R. S. D.; HILSCHER, A.; KNICKER, A. Depletion of soil organic carbon and nitrogen under Pinus taeda plantations in Southern Brazilian grasslands (Campos). European Journ I of Soil Science, Oxford, v. 60, n. 3, p. 311 - 487, 2009. 